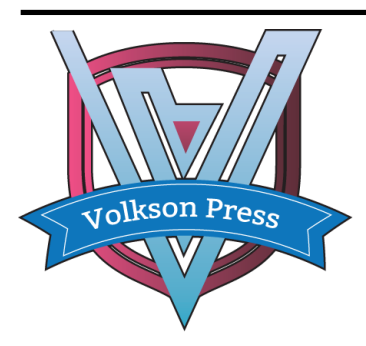

Contents List available at VOLKSON PRESS

New Materials and Intelligent Manufacturing (NMIM)

DOI : http://doi.org/10.26480/icnmim.01.2018.27.30

Journal Homepage: https://topicsonchemeng.org.my/

ISBN: 978-1-948012-12-6

\title{
ONLINE MONITORING OF BOILER LOW TEMPERATURE SUPERHEATER SURFACE POLLUTION BASED ON SVM
}

\author{
Yonggang Zhao' ${ }^{1}$ Yang Bai' ${ }^{1}$ Yuhui Chen ${ }^{2}$, Haiping Xiao², Zhizhong Kang², Baomin Sun ${ }^{2}$ \\ ${ }^{1}$ Shenhua group technology research institute, Xi 'an City, Shanxi Province 710065, China. \\ ${ }^{2}$ North China Electric Power University, Beijing 102206, China. \\ *Corresponding author email: 596884674@qq.com
}

This is an open access article distributed under the Creative Commons Attribution License, which permits unrestricted use, distribution, and reproduction in any medium, provided the original work is properly cited

\section{ARTICLE DETAILS}

\section{Article History:}

Received 26 June 2018

Accepted 2 July 2018

Available online 1 August 2018

\section{ABSTRACT}

The combustion of zhundong coal, which was rich in sodium and potassium, caused severe ash fouling in low temperature superheater. In this paper, according to the reason of the low temperature superheater ash fouling, the suitable characteristic parameters were selected, and a lot of relevant data were obtained from DCS system. A support vector machine model based on particle swarm optimization was proposed to predict the clean heat transfer in low temperature superheater surface using real operation data. In addition, the model was applied to the low temperature superheater of a 330MW unit and had a good prediction effect. The maximum accuracy rate reached above $99 \%$. Finally, a clean curve was drawn according to the historical data of one day, and it can reflect the low temperature superheater's pollution well.

\section{KEYWORDS}

Zhundong coal, fouling, clean heat transfer, low temperature superheater, SVM

\section{INTRODUCTION}

In recent years, with the increasing demand of electricity, the power plant unit in our country had gradually transited from subcritical to Super (super) critical. At the same time, the power plant's demand for coal was increasing. At present, China has explored Zhundong coalfield in Xinjiang, and its storage capacity reached an astonishing 400 billion tons [1]. But the content of alkali metals in Zhundong coal is pretty high, so there is a serious slagging and fouling phenomenon in the combustion of quasi-east coal. At present, China is trying to study and construct the boiler which can achieve full combustion of Zhundong coal. during the experiment, there are serious slagging phenomenon in different parts of boiler furnace [2]. Therefore, only by blending or additives, can the safe operation of the unit coal combustion process be maintained. In the boiler combustion coal with high sodium, low temperature heating surface was also very easy to foul.

Soot-blowing on the heat transfer surfaces was the most effective way to solve the above problems. Currently, coal-fired utility boilers in china preferred fixed-time and quantitative soot-blowing operation. Insufficient blowing will lead to low heat transfer efficiency, and then decreased the efficiency of the boiler. Frequent blowing will not only consume a lot of energy, but also cause damage to the heating surface of the boiler due to erosion and thermal stress, shortening the service life of the heating surface. Therefore, the monitoring of boiler heating surface and the improvement of soot blowing optimization have become one of the problems that need to be solved at present.

In recent years, many scholars had done a lot of work on the fouling monitoring of heat transfer surfaces. It was mainly divided into two types, one was based on the heat balance equation and formula calculation, according to the data from the DCS system, to calculate the heat absorption of the cleaning and the actual operation; the other was achieving the prediction of clean heat absorption using intelligent algorithm. A researchers took advantage of the artificial neural network to predict the heat absorption of the heating surface, and that and actual heat absorption were defined to realize the real-time monitoring of the fouling on the heating surface [3]. Another researcher using the principle of heat balance, a thermodynamic calculation model based on real-time data of power plant was established, which could be used to guide the soot-blowing of the convection heating surface of a power plant 600MW unit [4]. In other research paper, they calculated boiler thermal efficiency and reheater steam flow rate and the amount of blowing steam basing on dynamic mass stability and energy conservation methods online, and finally a reasonable soot-blowing scheme was formulated [5]. Basing on the principle of energy conservation and heat transfer, a computational model based on ash pollution loss was established by $\mathrm{Xu}$ huxiao et according to boiler efficiency and flue gas loss deviation.

Neural network method and support vector machine (SVM) are commonly used among many regression algorithms so far. Although both are based on the existing data for training and prediction, but support vector machines require fewer samples, need less training time and have higher accuracy. In the process of using SVM algorithm, two important parameters, $\mathrm{C}$ and $\mathrm{g}$, of kernel function were required to be optimized. In this paper, the particle swarm optimization (PSO)was used to optimize the parameters, and then the PSO-SVM model was obtained. Compared with the previous mathematical tools, the PSO-SVM algorithm has greatly improved the computation time and accuracy of the operation, which can provide a powerful basis for the on-line monitoring of the current large capacity super (super) critical unit. SVM overcomes the disadvantage of neural network falling into local minimum value, so it has better application prospect in classification and regression prediction [6].

In this paper, the thermal data in DCS system was preprocessed during modeling and calculating the boiler of a certain MW unit. Then, the intelligent learning calculation was carried out by using PSO-SVM to obtain the heat exchange under the ideal condition, and the cleaning coefficient of the low temperature superheater was deduced, which provided an effective reference for the on-line monitoring of fouling and slagging of large boiler. 


\section{ESTABLISHMENT OF FOULING MONITORING IN LOW TTEMPERATURE SUPERHEATER OF UTILITY BOILERS}

\subsection{Selection of Characteristic Parameters of Ash Fouling}

In the past, the fouling factor and the thermal effective coefficient were usually used as the monitoring parameters in the fouling monitoring system. But both of them need the parameters of the working medium side and the flue gas side, while the parameters of the flue gas side are difficult to detect directly, most of the high-temperature heating surface does not have outlet temperature measurement points except some lowtemperature heating surface. When the heating surface is polluted, the heat transfer of the heating surface is bound to be affected, and the more serious the fouling, the lower the heat exchange. Therefore, the ratio of the heat exchange of the convection heating surface during clean and practical time can be used to judge the degree of fouling in the heating area. A new characteristic parameter is cited to characterize the cleanliness of the heating surface-cleanliness factor $\mathrm{C}$.

$$
\mathrm{C}=\frac{\mathrm{q}_{\mathrm{act}}}{\mathrm{q}_{\mathrm{cle}}}
$$

Where qact is the heat exchange of each kilogram of steam on the low temperature superheater heating surface during the actual operation, and the qcle is the heat exchange of each kilogram of steam at the low temperature superheater heating surface under the corresponding load. The value of $\mathrm{C}$ lies in interval $[0,1]$. When the low temperature superheater surface is completely clean, $\mathrm{C}=1$; when low over heated area starts fouling, $\mathrm{C}$ decreases slowly. When there is no heat transfer, $\mathrm{C}$ turns to zero. So according to the change of the value of $\mathrm{C}$, real-time ash fouling monitoring of low temperature superheater surface can be achieved, providing guidance for power plant workers to carry out soot-blowing.

\subsection{Calculation of Low Temperature Reheater Heat Transfer}

In the actual operation of the boiler, the formula (2) can be used to calculate qact for each kilogram steam in the heating surface of the low temperature superheater.

$$
q_{a c t}=h^{\prime \prime}-h^{\prime}
$$

Where $h^{\prime \prime}$ is the enthalpy of the outlet of the heated surface, and H' is the enthalpy of inlet?

The steam pressure, temperature and flow rate of the heating surface can be obtained from the DCS system. According to the temperature and pressure, the enthalpy of the steam inlet and outlet can be calculated, and finally the heat transfer of the unit mass steam are obtained. However, under the corresponding load, the clean heat absorption of the heated surface cannot be obtained from Eqs. (2). The clean heat transfer under different degree of fouling was only related to some parameters in the actual operation of the boiler. clean heat absorption can be calculated according to the discrete data obtained from the DCS system in clean state, qcle showed a nonlinear change rule with the continuous change of time. The qcle at this time can be calculated by the SVM algorithm. This paper combined SVM with PSO algorithm, taking the data after long blowing or power plant overhaul collecting from the DCS system as input samples, which will be trained to obtain the mathematical model under the clean condition. Thus, the relationship between input and output can be got to predict the clean heat under not fully clean condition. Finally, the cleaning factor C was obtained from Eqs. (1).

\subsection{Selection of Operating Parameters}

The operating parameters related to the heat absorption of the low temperature heating surface can be determined by the following analysis. The two sides of the low temperature superheater were steam and flue gas respectively. The two parameters, flue gas volume and flue gas temperature, played a leading role in the influence of flue gas side. Most power plants did not have the temperature measurement point of the low temperature superheater, so the temperature of the flue gas was not considered. In the combustion process of the boiler, the volume of the delivery air was difficult to measure, so the flow rate, pressure and temperature of the low temperature superheater and the oxygen were used instead of flue gas flux. In addition, the combustion mode (i.e. the number of burners or the angle of the burner) can indirectly reflect the inlet flue gas temperature, so it can also be used as the input. The change of coal species had a great effect on the ash fouling of convective heating surface, so the coal-feed was considered as one of the input. For the steam side, the main influence factor was the physical properties of the steam itself, mainly including flow, pressure and temperature of steam.

According to the above theoretical analysis, the following relationship was constructed, which affected the cleaning heat absorption of the low temperature superheater: qcle $=\mathrm{f}$ (steam flow, steam pressure, steam inlet temperature, steam outlet temperature, burner tilt position, coal-feed, oxygen).

\section{INTRODUCTION AND FLOWCHART OF PSO-SVM ALGORITHM}

SVM can solve the problem of target classification and regression. Support Vector machine regression means pushing the conclusion of the indicator function into the regression function. In SVM regression method, it is usually divided into linear regression and nonlinear regression. In this account, solving the nonlinear regression problem is the main task, so the nonlinear regression principle of support vector machine was mainly introduced. For nonlinear regression, Vector $\mathrm{x}$ data is mapped to high dimensional feature spaces through nonlinear mapping by SVM. And linear regression is achieved in high-dimensional feature space, which transforms the problem of nonlinear function regression into linear function regression in high dimensional space, thus obtaining the effect of nonlinear regression in the original space [7].

Particle swarm optimization (PSO) is a new evolutionary algorithm, which has been developed by J. Kennedy and R. C. Eberhart in recent years. Starting from the random solution and searching for the optimal solution by iteration. Compared with genetic algorithm, the advantage of PSO is that its structure is simple and easy to implement, and the parameters need to be adjusted are few [8]. The general process of optimizing the support vector machine parameters by PSO is as follows:

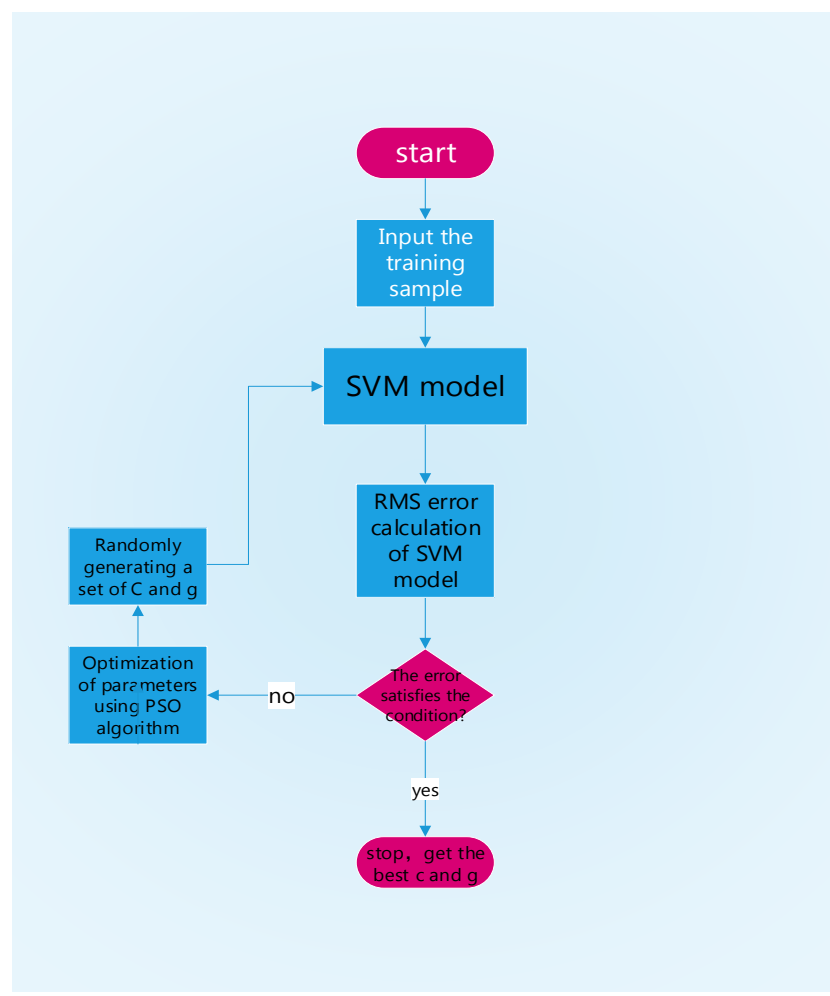

Figure 1: PSO-SVM algorithm parameter optimization

\section{MODEL ESTABLISHMENT AND VERIFICATION}

\subsection{Data Acquisition and Preprocessing}

Taking a 2*330 MW coal-fired unit as an example, this paper used the SVM as the core to establish a monitoring model of low temperature superheater to verify the accuracy of the on-line monitoring system. 
In this study, 100 groups of cleaning samples were extracted from the DCS system of power plant, and 80 sets of data were randomly sampled as training samples, and the remaining were used as the verification set.

\subsection{Model Establishment and Optimization of Parameters}

Because of the nonlinear relationship between independent variable and dependent variable, LIB-SVM software package was used to solve this model. Meanwhile, the radial basis function, which was superior to other kernel functions, was adopted [9]. The formula was as follows:

$$
K\left(x_{i}, x_{j}\right)=\exp \left(-g \cdot\left\|x_{i}-x_{j}\right\|^{2}\right)
$$

After the kernel function was selected, the original data was normalized, and the particle swarm algorithm was used to optimize the penalty $\mathrm{C}$ and kernel function parameter $g$ until the fitness function satisfied the requirement or reached the iterative number set by the PSO algorithm, then stopped the iteration to obtain the optimal parameters. The relevant parameters were set as follows: The maximum number of particle population was set to 20 , the maximum iteration number was 100 , the acceleration factor $\mathrm{c} 1$ and $\mathrm{c} 2$ both were 1.7, the optimization interval of penalty factor $\mathrm{C}$ was within $[0.001,100]$, and the optimization range of $\mathrm{G}$ was within $[0.01,100]$. After the particle swarm optimization, the penalty $\mathrm{C}$ is 68.9589, the kernel function parameter $\mathrm{g}$ is 0.01 and MSE equals 0.00028 .

Table 1 shows the maximum and minimum relative error and average relative error of the training set and test set calculated by the above model. Figure 1 shows the comparison curve of the actual clean heat absorption and the prediction of the clean heat absorption of the validation set in the model. This paper also draws a diagram (figure 2) of the relationship between the training set and the test set to verify the accuracy of the model.

Table 1: Prediction accuracy of GA-SVM model

\begin{tabular}{|l|l|l|l|l|}
\hline $\begin{array}{l}\text { Ite } \\
\mathrm{ms}\end{array}$ & $\begin{array}{l}\text { minimum } \\
\text { relative } \\
\text { error } \\
(\%)\end{array}$ & $\begin{array}{l}\text { maximum } \\
\text { relative error } \\
(\%)\end{array}$ & $\begin{array}{l}\text { average } \\
\text { relative error } \\
(\%)\end{array}$ & $\begin{array}{l}\text { Data } \\
\text { quantity }\end{array}$ \\
\hline $\begin{array}{l}\text { Training } \\
\text { Set }\end{array}$ & 0.07 & 3.08 & 1.45 & 80 \\
\hline $\begin{array}{l}\text { Testing } \\
\text { Set }\end{array}$ & 0.17 & 3.73 & 1.75 & 20 \\
\hline
\end{tabular}

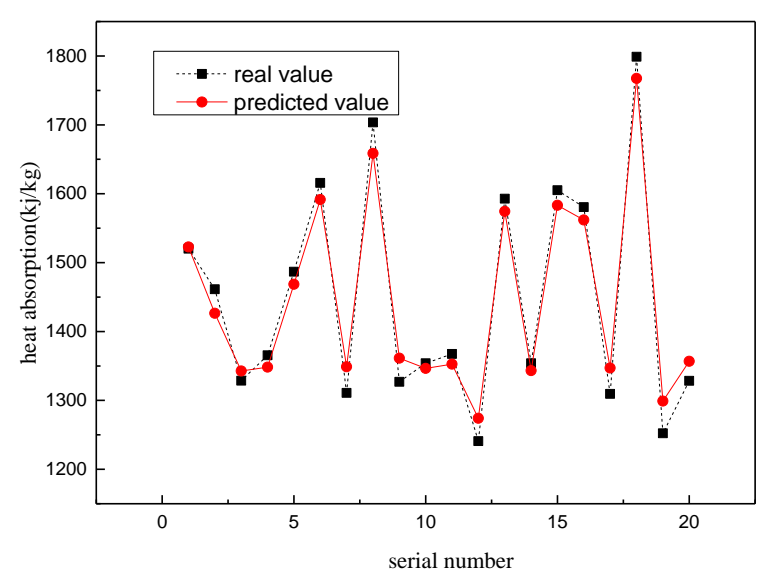

Figure 2: Heat absorption prediction of the model verification set

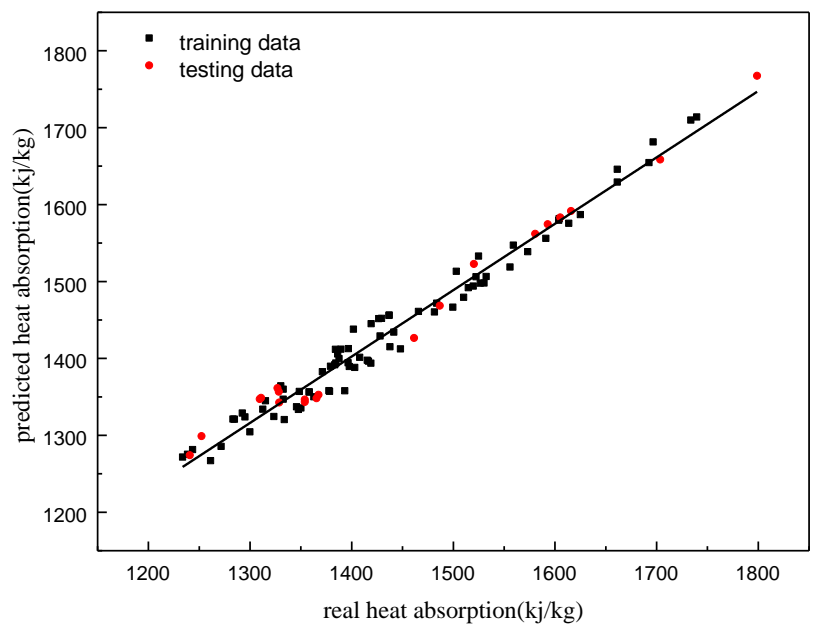

Figure 3: The relationship between the actual absorption of heat and the prediction of heat absorption

According to the data of Table 1 and Figure 1, it can be seen that the model has high accuracy. The average error of the training set and the test set is less than $2 \%$. The maximum relative error in Table 1 is also low, less than $4 \%$. The error of the test set is a little larger than the error of the training set, which is caused by the data of the training set involved in the intelligent learning of the model. The predicted value and the true value of heat absorption in the heated surface in Figure 2 are very close, which shows that the model can predict the ideal clean heat absorption of the lower temperature superheater surface well. As is shown in Figure 2, the sample data of the training set and the test set are evenly distributed on both sides of the line segment with a slope of one. This further illustrates that the results obtained by this model are very consistent with the real values.

\subsection{Modelling Verification}

This paper took a 330MW boiler as the research object, the 999 groups of thermal parameters under normal operating conditions were selected to calculate the actual heat absorption, then the cleaning heat absorption was predicted by the above model, and the cleanliness factor was calculated according to the Eqs. (1), and then the cleaning curve of the heating surface of the low temperature superheater was portrayed.

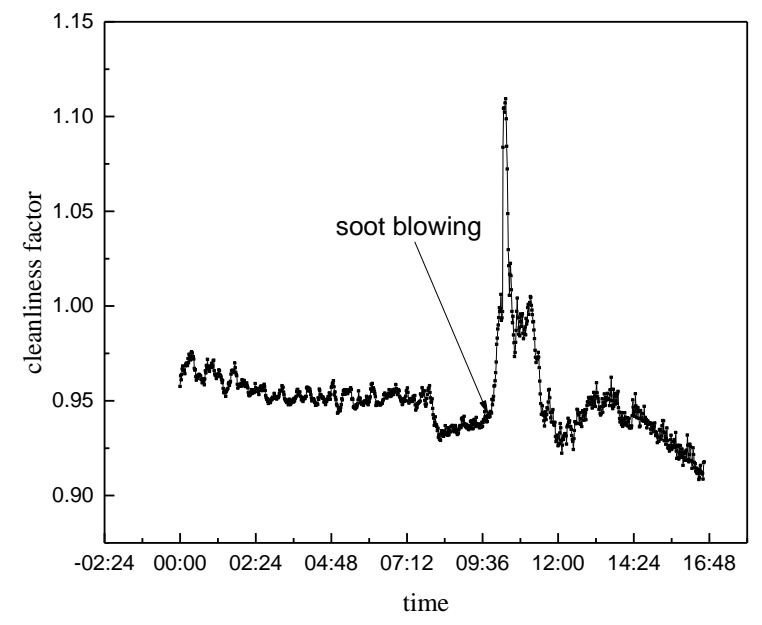

Figure 4: Cleaning curve of low temperature superheater's surfaces

From Figure 3, we can see that from the 0 o'clock to 7 o'clock in the morning, the cleanliness factor of the low temperature superheater changes not obviously nearly one, which indicates the heating surface is relatively clean in this period. After 7:30, the cleaning factor gradually decreases to the minimum and begins to fluctuate, indicating that the heat surface is continuously fouling in this period. When the soot-blowing starts, the cleanliness factor starts to increase suddenly and exceed the maximum value at the beginning. This may be due to the fact that the soot-blowing causes the heating surface to be cleaner than training, which results in the prediction of heat absorption larger than the ideal 
value. After the end of soot blowing, the cleanliness factor gradually decreases, which is caused by the beginning of the ash fouling in the heated surface, but not seriously.

\section{CONCLUSION}

Development of an accurate physical model for online monitoring of heat surface fouling in coal-fired boilers can be difficult due to complexity of the system. In this paper, we introduce a novel ensemble methodology with PSOSVM as base learner to set up the clean heat transfer model for low temperature superheater. The proper selection of training data and parameter is discussed in detail. The result of model indicate that the prediction accuracy is pretty high, reaching amost $99 \%$.

After comparison between clean heat absorption and real heat absorption, we can find that the cleanliness factor can reflect the pollution of the low temperature well and it can be achieved easier than using traditional physical calculation model. The heating surface cleaning curve can be used to judge when the soot-blowing is needed for coal-fired power plant operators.

\section{ACKNOWLEDGMENTS}

This project was funded by the National Key Technology R\&D Program of the Ministry of Science and Technology of China (No.2015BAA04B02). The authors would like to thank all of people who support help to us.

\section{REFERENCE}

[1] Changchun, G., Junqiu, H. 2012. Study on Coal Development and Coal Chemical in Dusty Scientific Development in Xinjiang [J]. Coal Economic Research, 32 (10), 13-24.

[2] Yang, B. 2017. Analysis of Slagging and Fouling Characteristics in a Purely Burning Zhundong Coal Boiler [J]. Clean Coal Technology, 23 (3), 118-123.

[3] Xiangliang, Y., Liansuo, A., Xinqiang, S. 2010. Real-Time Monitoring System for Ash Deposit in Utility Boiler Based on Artificial Neural Network [J]. Journal of Chinese Society of Power Engineering, 30 (3), 206-209.

[4] Xin, W., Bo, M., Wenguo, X. 2007. Research on Ash Monitoring of Convective Surfaces of $600 \mathrm{Mw}$ Coal-Fired U-Tility Boiler [J]. Jiangsu Electrical Engineering, (05), 63-65.

[5] Yuanhao, S., Jingcheng, W., Zhengfeng, L. 2014. On-Line Monitoring of Ash Fouling and Soot-Blowing Optimization for Convective Heat Exchanger in Coal-Fired Power Plant Boiler [J]. Applied Thermal engineering, 78, 39-50.

[6] Naseri, F., Jafari, F., Mohseni, E. 2017. Experimental Observations and Svm-Based Prediction of Properties of Polypropylene Fibers Reinforced Self-Compacting Composites Incorporating Nano-Cuo [J]. Construction and Building Materials, 143, 589-598.

[7] Vapnik, V. 1999. The Nature of Statistical Learning Theory [M]. New York: Springer Verlag.

[8] Yaqiong, L. 2017. Optimization of Genetic Algorithm Based on Particle Swarm Optimization [J]. Journal of Lanzhou University of Arts And Science (Natural Sciences), 31 (01), 55-60.

[9] Xinhong, L., Yuyun, B., Zhipeng, L. 2010. Analysis of Turbulence Structure in The Stirred Tank with A Deep Hollow Blade Disc Turbine by Time-Resolved Piv [J]. Chinese Journal of Chemical Engineering, 18 (4), 588-599 